\title{
NOVOS TÁXONS, NOVOS STATUS, NOVO SINÔNIMO E LECTOTIPIFICAÇÕES EM DIPLUSODON POHL (LYTHRACEAE)
}

\author{
TACIANABARBOSA CAVALCANTI
}

\author{
Embrapa Recursos Genéticos e Biotecnologia, Embrapa/Cenargen, Parque Estação Biológica, \\ Caixa Postal 02372, CEP 70.770-900, Brasilia, DF, Brasil. e-mail: taciana@cenargen.embrapa.br
}

\begin{abstract}
New taxa, new status, new synonym and lectotypifications in Diplusodon Pohl (Lythraceae). Three new species and one new variety are described and illustrated to Diplusodon: Diplusodon canastrensis and D. glocimarii, from Minas Gerais, D. cryptanthus and D. punctatus var. dentatus, from Goiás and Tocantins, respectively. Two new status, D. foliosus and D. petiolatus, D. paraisoensis synonym and two lectotypifications are presented.
\end{abstract}

Resumo - (Novos táxons, novos status, novo sinônimo e lectotipificações em Diplusodon Pohl (Lythraceae). Três novas espécies e uma nova variedade são descritas e ilustradas para o gênero: Diplusodon canastrensis e D. glocimarii, de Minas Gerais, D. cryptanthus e D. punctatus var. dentatus, de Goiás e Tocantins. Duas novos status, D. foliosus e D. petiolatus, um novo sinônimo, D. paraisoensis e duas lectotipificações são apresentadas.

Key words: Diplusodon, Lythraceae, taxonomy, Brazil.

\section{Introdução}

Desde 1985, diversas expedições de campo pelo Brasil estão sendo realizadas no sentido de aumentar o conhecimento das Lythraceae brasileiras, resultando em diversas publicações (Cavalcanti 1987, 1990, 1991, 1995, 1998, Graham \& Cavalcanti 2001, Cavalcanti et al. 2001) e reunindo informações que compõem a base de dados para a revisão do gênero Diplusodon. Esses esforços resultaram na coleção de muitas plantas interessantes da família, muitas delas representantes de espécies de ocorrência rara, endêmicas e representantes de táxons pouco representados em coleções, muitas vezes conhecidos apenas pelos materiais-tipo. É registrado um alto grau de endemismo para o gênero, que é refletido no fato de que, comumentemente, para cada região pouco explorada, se encontra táxons raros ou ainda não descritos. Desse modo, desde que se iniciou o trabalho de revisão do gênero, diversos materiais têm sido incorporados à investigação, via coletas próprias ou através de doações, muitos destes trazendo informações inéditas.

Diplusodon é um gênero de cerca de 76 espécies, distribuídas através da área contínua do Cerrado brasileiro e também nos cerrados da Bolívia (Cavalcanti \& Graham 1996). As espécies do gênero ocupam diferentes ambientes, incluindo bordas de matas de galeria, campos limpos sobre solo arenoso, cerrado denso com árvores e arbustos altos, cerrados abertos, campos sujos e campos rupestres. Do mesmo modo que os ambientes ocupados são bem diversificados, os hábitos destas plantas são variáveis. Ocorrem desde espécies que alcançam até $4 \mathrm{~m}$ de altura com tronco fino e bem definido, caracterizando uma arvoreta, até plantas arbustivas, subarbustivas e hemicriptófitas com evidente xilopódio (Cavalcanti 1995).

De forma geral, o gênero Diplusodon pode ser caracterizado por plantas com folhas opostas, flores regulares, hexâmeras e períginas, com duas bractéolas (profilos) e um epicálice com seis apêndices. O androceu pode ser isostêmone, obdiplostêmone ou polistêmone (Cavalcanti 1995). O gineceu é bicarpelar e unilocular com um septo incompleto. $\mathrm{O}$ fruto é uma cápsula septicida com sementes aladas. A etimologia do gênero refere-se às sépalas do cálice e apêndices do epicálice, verticilos estes que juntos formam duas fileiras de "dentes" (diplus=duplo; odon=dente).

As espécies de Diplusodon foram estudadas de forma abrangente por Koehne (1903) que utilizou os espécimes coletados no século XVIII para a sua análise. Um trabalho mais recente, a sinopse apresentada por Lourteig (1989), acrescenta 18 novas espécies ao gênero. Com a exploração minuciosa de novas localidades, especialmente em áreas localizadas na região central do país, considerada a região de diversidade primária do gênero (Cavalcanti 1995), não é raro a descoberta de novos táxons. Cavalcanti (1998) descreve nove novos táxons e o atual trabalho apresenta mais novidades para o grupo. Os dados divulgados são parte da revisão do gênero que está sendo preparada para a série Flora Neotrópica.

\section{Diplusodon canastrensis T.B. Cavalc., sp. nov. (Fig. 1)}

A D. myrsinites habitu, segmentis epicalycis suberetis et minoribus, segmentis epicalycis prophyllisque diminuto ciliati differt.

Typus: Brasil. Minas Gerais: Sacramento, Parque Nacional da Serra da Canastra. Estrada São Roque de MinasSacramento, a $41 \mathrm{~km}$ da portaria de São Roque de Minas, 7.XI.2002 (fl, fr), R. Mello-Silva et al. 1973 (holotypus: CEN; isotypi: BHCB, G, HUFU, K, MBM, NY, RB, SP, SPF).

Arbustos 0,40-0,60 m alt., densos, muito ramificados; ramos eretos, os superiores quadrangulares, diminutamente alados, delgados, congestos, tenuamente pilosos, tricomas diminutos, inconspícuos, internós 3-8 mm compr., folhas 


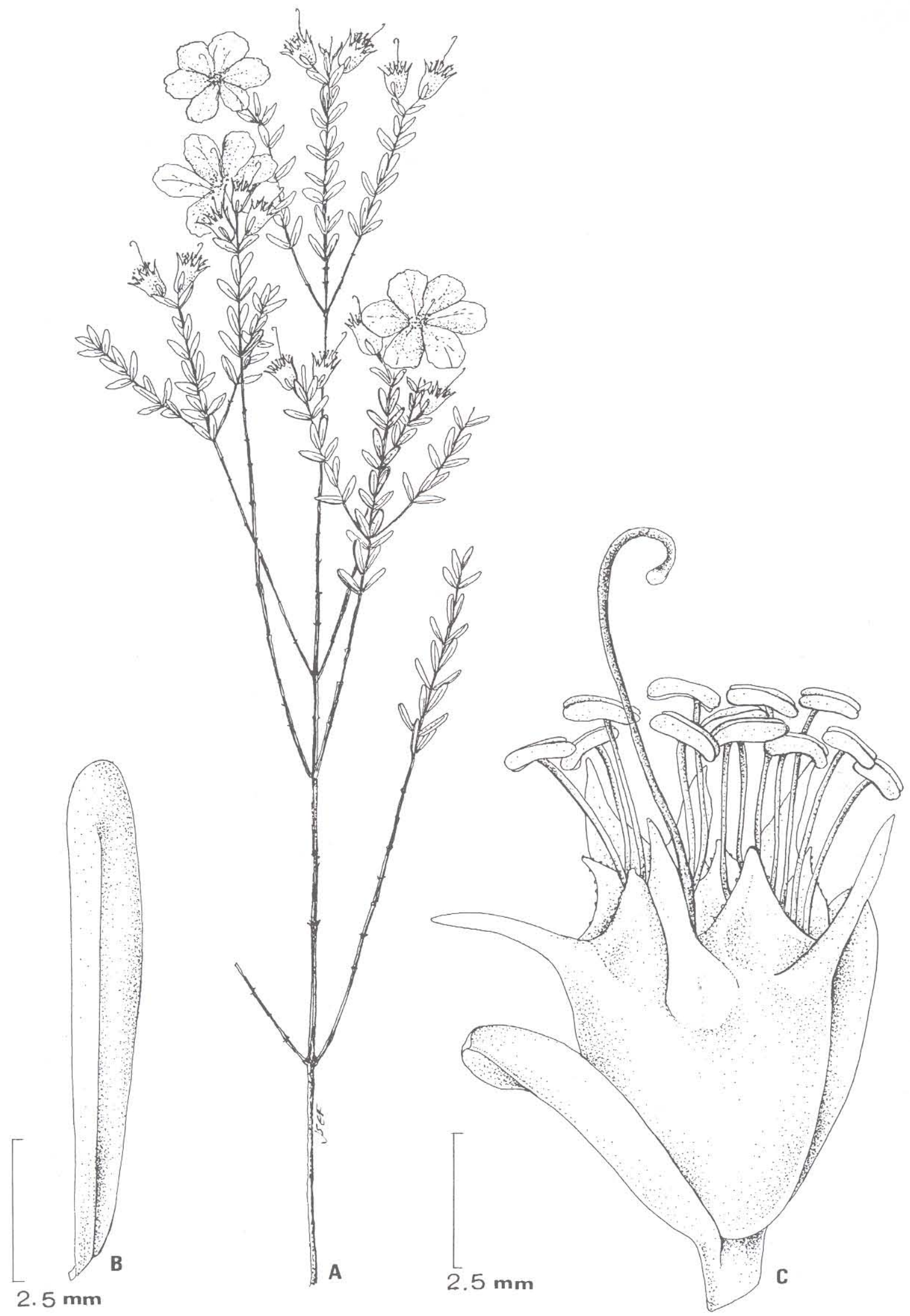

Fig. 1: Diplusodon canastrensis T. Cavalcanti. A. ramo ilustrando parte do hábito; B. folha, face adaxial; C. flor, sem as pétalas, mostrando a relação profilos/sépalas/segmentos do epicálice (A-C: Nakajima et al. 1591). 
caducas nos ramos mais velhos. Folhas dos ramos superiores 5-7 mm compr., 1-2 mm larg., decussadas, sésseis, eretas, hifódromas, coriáceas, oblongo-lineares, ápice obtuso, margem plana, levemente hialina, às vezes diminutamente ciliada por tricomas muito curtos e esparsos, base atenuada, lâminas glabras, nervuras laterais pouco evidentes, 1 de cada lado, nervura central proeminente na face abaxial, sulcada na face adaxial. Sinflorescência frondosa do tipo pleiobótrio, florescência principal não caduca, paracládios $5-10 \mathrm{~cm}$ compr., brácteas semelhantes às folhas vegetativas; flores pediceladas, hipopódio 1,5-2 mm compr., epipódio 0-0,5 mm compr., diminutamente pilosos, profilos 4,5-5,5 mm compr., 1,5-1,8 mm larg., oblongo-lineares a estreito-obovais, glabros, ápice obtuso, margem plana, raro com tricomas muito curtos, alcançando a ultrapassando o ápice do tubo floral, tubo floral 4,5-5 mm compr., infundibuliforme, verde-claro, glabro ou com tricomas inconspícuos, sépalas 3-3,5 mm compr., triangulares com ápice atenuado, curtamente caudado, avermelhadas, glabras, margem levemente hialina, curtamente ciliada com tricomas diminutos, esparsos, tricomas curtos concentrados no ápice, segmentos do epicálice 3-3,5 mm compr., achatados, suberetos, com nervura central avermelhada, alcançando as sépalas, margem levemente hialina, curtamente ciliados com tricomas diminutos, esparsos, glandulares na face interna na região do ápice; corola lilás a rosa-escuro, ca. $2 \mathrm{~cm}$ diâm., pétalas 9-10 mm compr., 7,5-8 mm larg., largo-obovais, ápice obtuso a emarginado; estames 12 , porção livre dos filetes 6-7 $\mathrm{mm}$ compr., exsertos ca. $1 \mathrm{~mm}$, vináceos; ovário ca. 1,2 mm compr., 2 mm larg., rômbico, glabro, estilete 10-11 mm compr., rosa-escuro, estigma conspicuamente papiloso, óvulos 12 13. Cápsula arredondada, sementes ca. 35, 2-2,5 mm compr., $1,8-2 \mathrm{~mm}$ larg.

Paratypi: Brasil. Minas Gerais: São Roque de Minas, Serra Brava, próximo ao mirante, 28.IX.1995 (fl), R. Romero et al. 2980 (CEN, HUFU); 23.XI.1995 (fl), J.N. Nakajima et al. 1591 (CEN, HUFU); estrada para o Vale dos Cândidos, Garagem de Pedras, Parque Nacional da Serra da Canastra, 22.VIII.1997 (fl), J.N. Nakajima et al. 2694 (CEN, HUFU).

Diplusodon canastrensis é endêmico das montanhas do Parque Nacional da Serra da Canastra, crescendo em solo areno-pedregoso de campos rupestres e campos sujos. A espécie apresenta várias características que a tornam um táxon diferenciado de espécies mais estreitamente relacionadas. Os indivíduos são pequenos arbustos densamente ramificados, aspecto que associado ao pequeno diâmetro de suas flores, lembram, no campo, o hábito de algumas espécies de Microlicia (Melastomataceae) (Mello-Silva com. pes.). As folhas são pequenas, oblongas e estreitas e, à primeira vista, a planta aparenta ser totalmente desprovida de indumento. Examinando os espécimes sob lupa, observa-se que os ramos, a margem das folhas, profilos e sépalas e o tubo floral portam minúsculos tricomas, esparsos e pouco perceptíveis. Com relação aos caracteres florais, a espécie apresenta profilos alcançando a ultrapassando o tubo floral. Os segmentos do epicálice são eretos, achatados, alcançando o ápice das sépalas e na face interna apical apresentam glândulas vermelho-translúcidas. As sépalas são caudadas e com papilas secretoras conspícuas na margem interna.

Diplusodon canastrensis faz parte do grupo de espécies que apresentam folhas com nervuras insconspícuas e androceu com 12 estames. Neste grupo assemelha-se a $D$. myrsinites, espécie das serras do sul da Cadeia do Espinhaço, em Minas Gerais, especialmente pelas folhas pequenas e glabras, mas que são obovais a elípticas e geralmente com 5$12 \mathrm{~mm}$ de largura. Além disso, D. myrsinites diferencia-se também pelos ramos virgados com folhagem laxa, segmentos do epicálice mais curtos e patentes e os profilos menores, alcançando até a metade do tubo floral. Enquanto que em $D$. canastrensis, o hábito é congesto e muito ramificado, os ramos são eretos, as folhas oblongo-lineares com 1-2 mm de largura e os profilos são mais longos, chegando a ultrapassar o tubo floral.

Diplusodon canastrensis floresce de agosto a novembro e frutos imaturos foram encontrados em novembro.

2. Diplusodon cryptanthus T.B. Cavalc., sp. nov. (Fig. 2)

Foliis 13-25 mm latis, apicibus acutis, basibus obtusis, prophyllis ovatis tubum floralem involventibus, pedicelli usque ad $2.5 \mathrm{~cm}$ longi distinguitur. A D. longipes Koehne et D. marginatus Pohl habitu caespitoso, foliis majoribus, ample ovalibus, amplexicaulibus et corolla $5-7 \mathrm{~cm}$ diam. differt.

Typus: Brasil. Goiás: Minaçu, $2 \mathrm{~km}$ ao $\mathrm{N}$ do antigo aeroporto do canteiro de obras do UHE Serra da Mesa, $13^{\circ} 28^{\prime} \mathrm{S}, 48^{\circ} 23^{\prime} \mathrm{W}$, 9.III.1992 (fl), T.B. Cavalcanti et al. 1053 (holotypus: CEN; isotypi: $\mathrm{SPF}, \mathrm{UFG})$.

Arbusto 0,60-1(-2) m alt., com xilopódio, corimbiforme, folhagem congesta; ramos inferiores pilosos, superiores glabros, virgados, subquadrangulares com pequena ala, avermelhados, internós 1-2 cm compr. Folhas 40-57 mm compr., 13-25 mm larg., patentes a suberetas, decussadas, acródromas supra- numerárias, cartáceas a membranáceas, subsésseis, glabras, levemente glaucas, subsésseis, ovais a elíptico-lanceoladas, ápice agudo, margem plana, às vezes ciliadas, base obtusa, nervuras 2-3 de cada lado, sendo 2 partindo da base da nervura central, proeminentes na face abaxial, inconspícuas na face adaxial. Sinflorescência frondoso-bracteosa do tipo triplobótrio a pleiobótrio, florescência principal do tipo bótrio, ca. $5 \mathrm{~cm}$ compr., paracládios 3-13 cm compr., brácteas 10-50 mm compr., 6-20 $\mathrm{mm}$ larg., mais estreitas que as folhas vegetativas, formando domáceas evidentes; flores pediceladas, hipopódio 15-25 mm compr., epipódio 2-2,5 mm compr.; profilos 13-25 mm compr., 9-12 mm larg., ovais a elíptico-lanceolados, ápice obtuso, margem plana, encobrindo totalmente o tubo floral; tubo floral 7-8 mm compr., estreito-oblongo, sépalas $2-3 \mathrm{~mm}$ compr., 


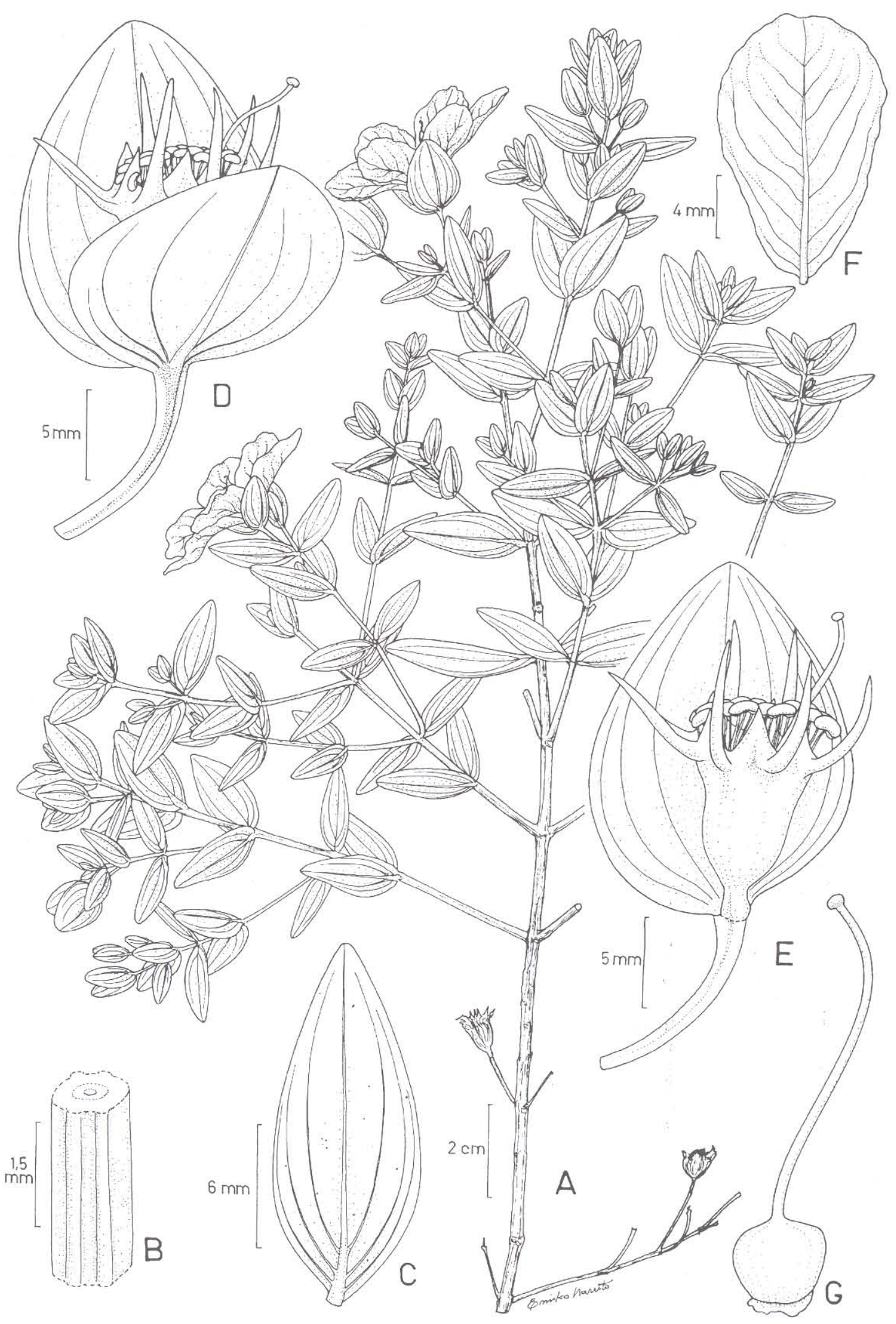

Fig. 2: Diplusodon cryptanthus T. Cavalcanti. A. parte da inflorescência; B. seção transversal do ramo superior; C. folha, face abaxial; D. flor oculta pelos profilos, sem as pétalas,; E. flor, removidas as pétalas e um dos profilos, mostrando a relação sépalas/segmentos do epicálice: profilo/tubo floral; F. pétala, G. pistilo. (A-G: Cavalcanti et al. 1053). 


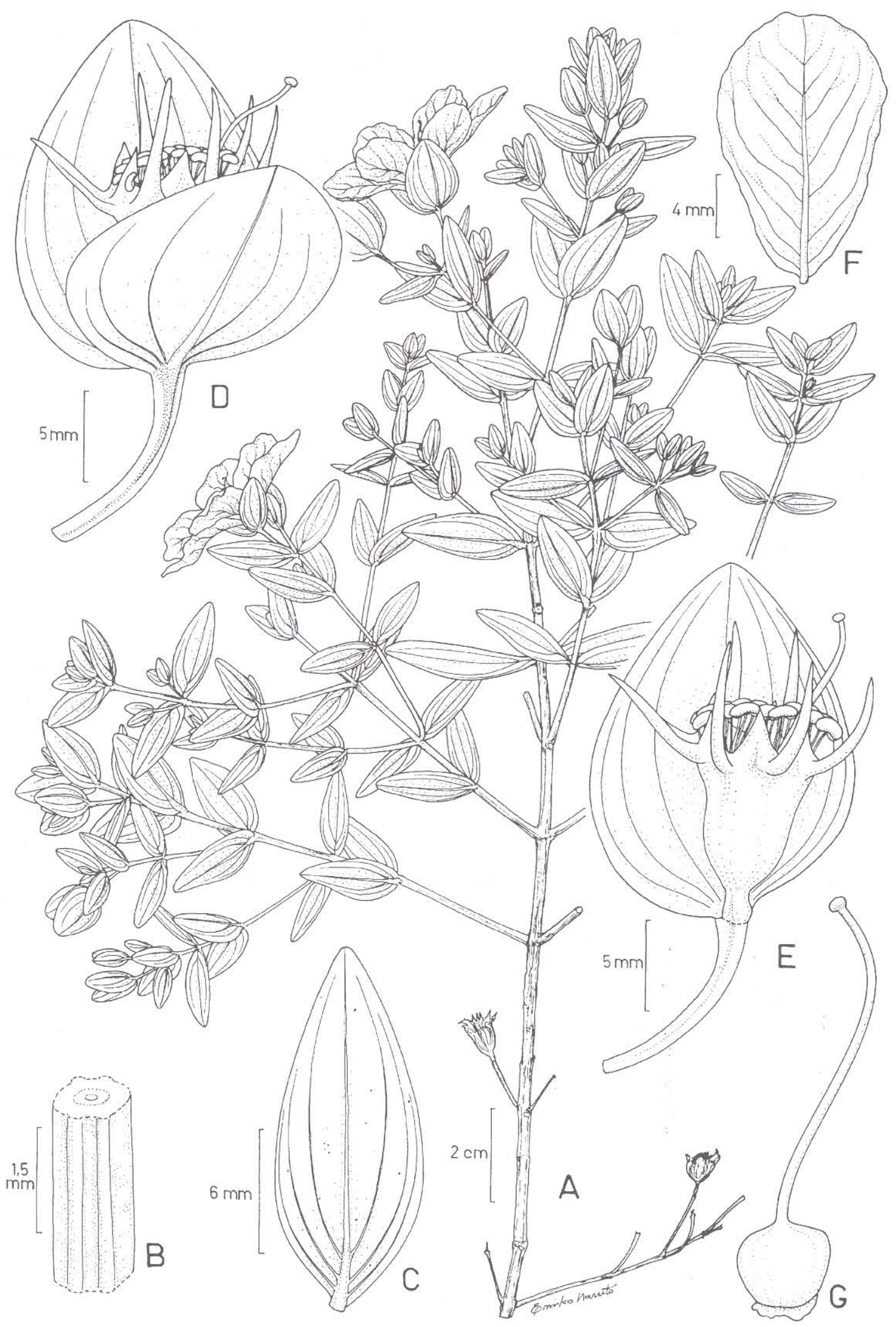

Fig. 2: Diplusodon cryptanthus T. Cavalcanti. A. parte da inflorescência; B. seção transversal do ramo superior; C. folha, face abaxial; D. flor oculta pelos profilos, sem as pétalas,; E. flor, removidas as pétalas e um dos profilos, mostrando a relação sépalas/segmentos do epicálice; profilo/tubo floral; F. pétala, G. pistilo. (A-G: Cavalcanti et al. 1053). 
triangulares, vináceas; segmentos do epicálice 6-8 $\mathrm{mm}$ compr., levemente achatados, lineares, verdes, eretos; corola até 4,5 cm diâm., rosa a arroxeada, pétalas $16-17$ mm compr., obovais; estames (15) 18, porção livre dos filetes 7-8 mm compr., exsertos ca. $2 \mathrm{~mm}$; ovário 2,5-3 mm compr., 3-4 mm larg., rômbico, glabro, estilete ca. 14-15 mm compr., óvulos 26-35. Cápsula urceolada, sementes 19-30, 1,5-2,1 mm compr., 2-3 mm larg.

Paratypi: Brasil. Goiás: Campinaçu, depois de Buriti, 18

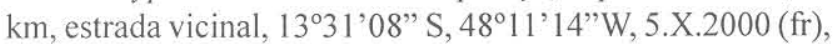
T.B. Cavalcanti et al. 2661 (CEN); estrada de asfalto Campinaçu-Minaçu, 1336'42”S, 48²0'21'W, 4.X.2000 (fr), T.B. Cavalcanti et al. 2595 (CEN); estrada Vila Veneno-Serra Branca, $\mathrm{km}$ 3,6 (margem direita do rio Macacão), 1334'25"S, 4804'20"W, 20.II.2002 (fr), G. Pereira-Silva et al. 5898 (CEN). Cavalcante, ca. $4 \mathrm{~km}$ da vila Veneno em direção ao rio São Felix, 1331'36"S, 4803'45"W, 25.I.2001 (fl), G. Pereira-Silva et al. 4655 (CEN); ca. $3,5 \mathrm{~km}$ canteiro da obra para o rio do

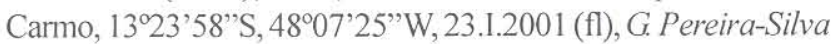
et al. 4585 (CEN); $2 \mathrm{~km}$ à leste da ponte sobre o rio Tocantins, na direção de Cavalcanti, 132ㄱ'43"S, 4807'56"W, 20.II.2002 (f1), G. Pereira-Silva et al. 5871 (CEN); canteiro de obras do AHE Cana Brava, próximo à estação de tratamento de água, 22.V.2001 (fr), G. Pereira-Silva et al. 5057 (CEN, NY); canteiro da obra, rio do Carmo, $\mathrm{km} \mathrm{01}$, próximo a porteira trancada, 13⒉'43"S, 4807'56"W, 10.VII.2001 (fr), G. Pereira-Silva et al. 5226 (CEN); estrada para Limoeiro, ca. $20 \mathrm{~km}$ da balsa (Porto dos Paulistas) rio Tocantins, $13^{\circ} 26^{\prime} 12^{\prime \prime} \mathrm{S}, 48^{\circ} 03^{\prime} 44^{\prime \prime} \mathrm{W}$, 21.II.2001 (fl), G. Pereira-Silva et al. 4718 (CEN); estrada para Limoeiro, ca. $28 \mathrm{~km}$ da balsa (Porto dos Paulistas) rio Tocantins, 1329'34'S, 4803'04"W, 21.II.2001 (fr), G. PereiraSilva et al. 4736 (CEN). Colinas do Sul, Fazenda Cigarra, próximo ao rio Tocantins, $13^{\circ} 38^{\prime} 27^{\prime}$ 'S , 48 $08^{\circ} 3$ l' $^{\prime} \mathrm{W}, 19 . \mathrm{IV} .2001$ (f1), G. Pereira-Silva et al. 4991 (CEN). Tocantins: Palmeirópolis, rodovia Minaçu-Palmeirópolis, km 57 após Minaçu, 1303'34"S, 48²3'34"W, 21.11.2002 (fl), G. PereiraSilva et al. 5908 (CEN).

Diplusodon cryptanthus pode ser identificado pelo pedicelo longo de até $2,5 \mathrm{~cm}$ de compr. e pelos profilos amplos e ovais, que ocultam completamente o tubo floral. Essas características são compartilhadas com $D$. longipes e $D$. marginatus, espécies também de Goiás. Entretanto essas espécies diferem de $D$. cryptanthus por possuírem ramos não virgados, com seus ramos partindo de forma cespitosa diretamente de um xilopódio, folhas maiores, amplamente ovais, de base amplexicaule, inflorescência laxa e corola de cinco a sete centímetros de diâmetro.

A distribuição de Diplusodon cryptanthus limita-se, segundo o conhecido atualmente, ao norte da Serra Geral do Paranã, no norte do estado de Goiás e sul de Tocantins. A espécie pode ser encontrada nas formações cerrado aberto e campos sujos, em solos arenosos com quartzo leitoso e em solos areno-argiloso com cascalho. Floresce de janeiro a abril e frutifica de maio a outubro.
3. Diplusodon foliosus (Koehne) T.B. Cavalc., comb. et stat. nov. (Fig. 3)

Basiônimo: Diplusodon lanceolatus Pohl var. alutaceus (Pohl) Koehne f. foliosus Koehne, Fl. bras. 13 (2): 330. 1877. Typus: Brasil. Goiás: 1841, G. Gardner 3721 (lectotypus: P; isolectotypi: $\mathrm{G}, \mathrm{K}, \mathrm{NY}, \mathrm{P}, \mathrm{W}$, aqui designado).

Diplusodon paraisoensis Lourteig, Bradea 5 (19): 240, pr. 3, fig. a-f. 1989. Typus: Brasil. Goiás: Chapada dos Veadeiros, Alto Paraíso de Goiás, 21.III.1969 (fl), H.S. Irwin et al. 24793 (holotypus: P; isotypus: NY), syn. nov.

Subarbustos com xilopódio, 0,40-3 m alt.; ramos subquadrangulares, às vezes cinéreos e brilhantes, estrigosos, internós 1-3 cm compr. Folhas 25-50 mm compr., 10-25 mm larg., patentes a suberetas, decussadas, acródromas basais supranumerárias, coriáceas, canescentes, subsésseis, ovais a oblongo-lanceoladas, ápice agudo a obtuso, acuminado, margem plana, base cordada a subcordada a obtusa, lâminas verrucosas devido à base bulbosa dos tricomas, face adaxial estrigosa, face abaxial estrigosa com tricomas mais abundantes e alvos, às vezes abundantes e concentrados tornando a folha esbranquiçada, às vezes esparsos e pouco visíveis, nervuras 4-7 de cada lado, 3-4 saindo da base da nervura central, pecíolo largo, 1-3 mm compr. Sinflorescência frondoso-bracteosa do tipo triplobótrio a pleiobótrio, florescência principal $4-6 \mathrm{~cm}$ compr., paracládios 6-25 cm compr., brácteas 10-27 mm compr., 6-10 mm larg., semelhantes às folhas vegetativas em forma; epipódio 1-2 mm compr.; profilos 9,5-11 mm compr., 2,5-4,5 mm larg., elíptico-lanceolados, pilosos, ápice agudo, base obtusa a aguda, margem plana, ultrapassando o ápice do tubo floral; tubo floral 5,5-7 $\mathrm{mm}$ compr., infundibuliforme, densamente piloso, esbranquiçado, aumentado de tamanho no fruto, sépalas 3-6 mm compr., triangulares, vináceas, pilosas, segmentos do epicálice 4,3-6 $\mathrm{mm}$ compr., esverdeados a vináceos, pilosos, triangulares expandidos ou com margens subrevolutas, patentes a suberetos, alcançando a altura das sépalas a maiores; corola 5-6 cm diâm., rosa-clara a lilás, às vezes rosa-choque, pétalas $18-25 \mathrm{~mm}$ compr., 12-15 mm larg., obovais, ápice obtuso às vezes emarginado; estames 25-32, exsertos 5-6 mm, porção livre dos filetes 10$14 \mathrm{~mm}$ compr., rósea, ultrapassando as sépalas ca. $1 \mathrm{~mm}$; ovário 2, 1-2,8 mm compr. 3-3,7 mm larg., obcônico, glabro, estilete 14-21 mm compr., estigma atrovioláceo; óvulos 3680. Cápsula arredondada; sementes (37-) 50-72, 3,5-4 mm compr., 3-3,5 mm larg.

Material examinado: Brasil. Goiás: Água Fria, 1502'53"S, 47³6’06"W, 27.I.1997 (f1), B.M.T. Walter et al. 3631 (CEN); Estação Repetidora da Telebrasília de Roncador, 8.II.1994 (fl), G. Hastchbach et al. 60152 (MBM). Alto Paraíso de Goiás, $14^{\circ} 07^{\prime}$ 'S, $47^{\circ} 26^{\prime} \mathrm{W}, 13.111 .1995$ (fl), T.B. Cavalcanti et al. 1309 (CEN); 1406'09"S, 47²8'47"W, 3.IV.1997(fr), T.B. Cavalcanti et al. 2199 (CEN, NY); 135'12"S, 47²5'12"W, 4.IV.1997, T.B. 


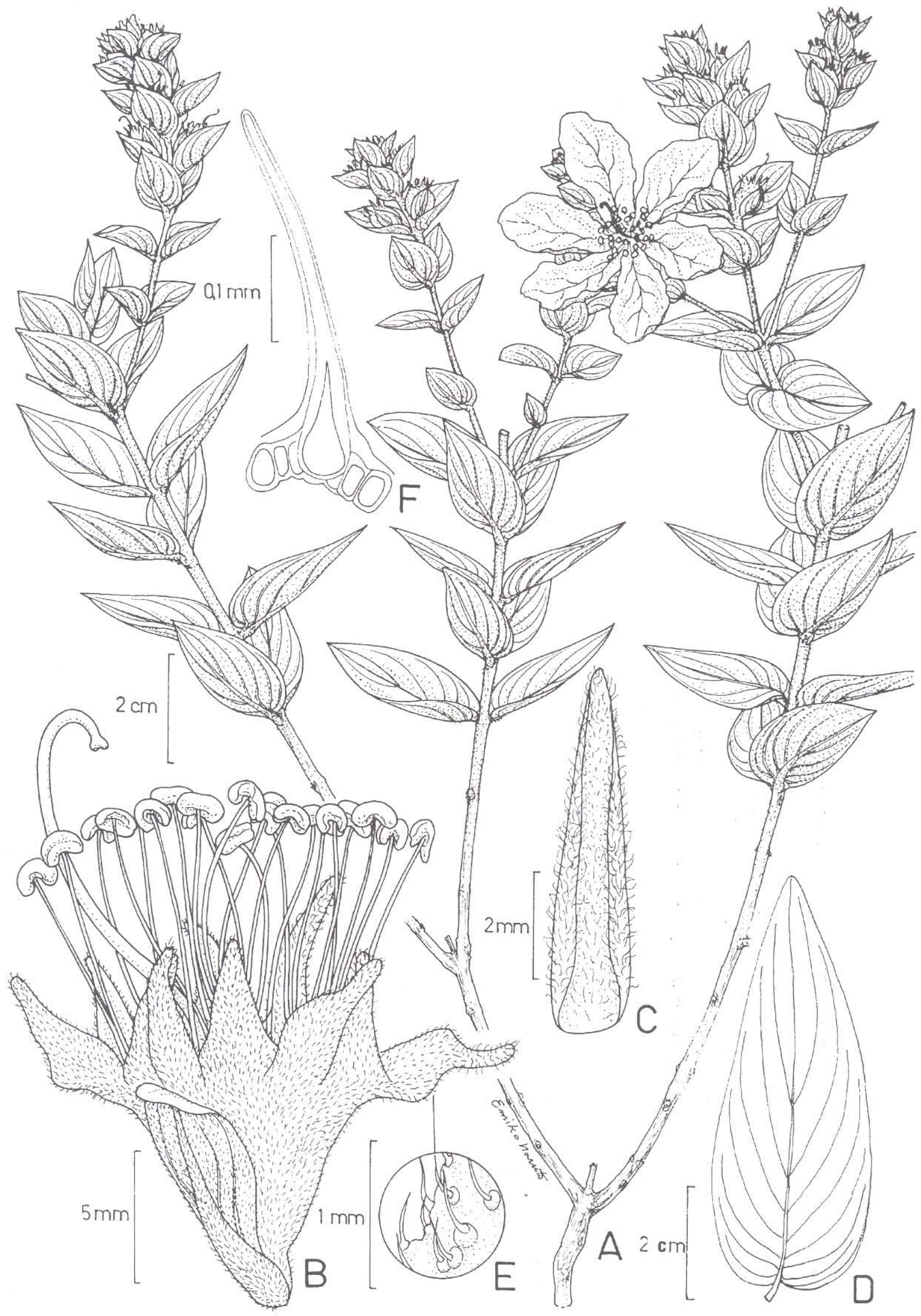

Fig. 3: Diplusodon foliosus (Koehne) T. Cavalcanti. A. ramo ilustrando parte do hábito. B. flor sem as pétalas. C. segmento do epicálice, face abaxial. D. folha, face abaxial. E. detalhe do indumento da flor. F. tricoma. (A-C, E-F: Cavalcanti et al. 390, D: Cavalcanti et al. 1259). 
Cavalcanti et al. 2205 (CEN); $1 \mathrm{~km} \mathrm{~L}$ de Alto Paraíso na estrada para Nova Roma, 5.III.1973 (fl), W.R. Anderson 6336 (NY, P, UB); 6-7 km L de Alto Paraíso na estrada para Nova Roma, 7.III.1973 (fl), W. Anderson 6506 (NY, n.v., P, n.v., UB). Arraias, estrada GO-118, Campos Belos-Arraias, a $9 \mathrm{~km}$ da saída de Campos Belos, 1259'69”'S, 4650’46"W, 5.IV.1997 (fl, fr), T.B. Cavalcanti et al. 2217 (CEN, KE, NY). Campos Belos, 21.III.1993 (fl), T.B. Cavalcanti et al. 1259 (CEN); entre Arraias e Campos Belos, 8 km de Campos Belos no sentido Arraias, 21.III.1993 (fl), T.B. Cavalcanti et al. 1259 (CEN, MBM, R, SPF); estrada Campos Belos para a Chapada dos Veadeiros, 6.IV.1972 (fl, fr), J.A. Rizzo 7978 (UFG). Cavalcante, estrada velha para Nova Roma, a $7 \mathrm{~km}$ do entroncamento Teresina de

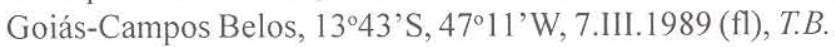
Cavalcanti et al. 390 (CEN, NY, SPF); $21 . I I I .1993$ (fl), T.B. Cavalcanti et al. 1257 (CEN); $10 \mathrm{~km} \mathrm{~S} \mathrm{de} \mathrm{Teresina,} \mathrm{27.V.1975,}$ G. Hatschbach et al. 36914 (MBM, n.v., P); entre Cavalcante e Conceição, Burchell 8011 (K). Niquelândia, Fazenda Serra Negra, Serra Negra, ao lado da linha de transmissão elétrica, 11.VI. 1992 (fl, fr), B.M.T. Walter et al. 1617 (CEN, NY). Planaltina, GO-118, km 110, 20 km S de São João da Aliança, 14.IV. 1994 (fl, fr), T.B. Cavalcanti \& G. Pereira-Silva 1264 (CEN, SPF). São João da Aliança, 10 km N de São João da Aliança, 18.II.1975 (fl), G. Hatschbach et al. 36257 (MBM, P); GO-3, a $72 \mathrm{~km}$ do entroncamento da BR-020-DF-345, 15.VIII.1990 (fr), T.B. Cavalcanti et al. 648 (CEN, K, NY, SPF); GO-118, 10-20 km S de São João da Aliança, 11.II.1990 (fl), G. Hatschbach \& V. Nicolack 53813 (MBM, NY); $65 \mathrm{~km} \mathrm{~S}$, 27.II.1982 (fl), P.I. Oliveira \& W.R. Anderson 474 (MBM, US). Teresina de Goiás, estrada Alto Paraíso-Teresina de Goiás, a $59 \mathrm{~km}$ de Alto Paraíso, local de camping próximo à cachoeira, Hotel Ecológico Alpes Goianos, 1351'54"S, 47¹5'55"W, 4.IV.1997 (fl, fr), T.B. Cavalcanti et al. 2210 (CEN, KE, NY). Sem referência do município, 1839 (fr), G. Gardner 3152 (K); 9.XI.1991, G. Hastchbach et al. 55995 (MBM, n.v., P). Tocantins: Natividade, Serra da Natividade, a uns $20 \mathrm{~km}$ de Natividade, 12.IV.1974, J.A. Rizzo 9877 (UFG). Pindorama do Tocantins, $11^{\circ} 26^{\prime} 47^{\prime \prime} \mathrm{S}, 47^{\circ} 41^{\prime} 40^{\prime \prime} \mathrm{W}$, estrada de terra para Pindorama do Tocantins, a $18 \mathrm{~km}$ do entrocamento com Ponte Alta, 13.VI.2002 (fl), Cavalcanti et al. 2738 (CEN). Porto Nacional, estrada Porto Nacional-Brejinho de Nazaré, próximo à Fazenda Amélia, 1100'34"S, 4854'71"W, 27.V.1999, R. G. Lira \& W. Noleto s.n. (HTINS).

Koehne (1877), baseando-se no material de Gardner 3721, descreve Diplusodon lanceolatus var. alutaceus f. foliosus, indicando para este táxon características como ramos e folhas velutinas e congestas e flores com 22-26 estames.

O material de Gardner 3721 apresenta, além das características citadas acima, folhas ovais a oval-elípticas de base cordada a obtusa, cobertas por tricomas de base espessada, flores com 9-11 mm de comprimento, segmentos do epicálice setáceos e longos e androceu com 24-32 estames. Com base nessas características reconhece-se um novo táxon ao nível específico, com morfologia bastante diferente de D. lanceolatus.
O material Gardner 3721 possui duplicatas em diferentes herbários. Entre as três exsicatas do Herbário P, uma delas possui uma ficha mais completa além de um exemplar que apresenta, além da inflorescência, também folhas do ramo vegetativo. Este material foi escolhido como lectótipo.

Lourteig (1989), também utiliza essas características para nomear uma nova espécie, $D$. paraisoensis, sem se ater ao fato que $D$. lanceolatus var. alutaceus $\mathrm{f}$. foliosus (Gardner 3721 ) trata-se da mesma entidade. Dessa forma, nesse trabalho elege-se o novo status para o nome proposto por Koehne (1877) e efetua-se a sinonimização de D. paraisoensis.

Diplusodon foliosus ocorre em Goiás e Tocantins, em áreas de cerrado (sensu stricto) e campo sujo, entre 660 a $1300 \mathrm{~m}$ s.n.m. Floresce em janeiro e fevereiro e frutifica a partir do mês de abril.

\section{Diplusodon glocimarii T.B. Cavalc., sp. nov. (Fig. 4)}

Foliis ellipticis, basibus attenuatis, trichomatibus argenteis ornatis, petiolatis, petiolis usque ad $4,0 \mathrm{~mm}$ longis, inflorescentia densiflora, floribus 12 staminibus praedita distinguitur.

Typus: Brasil. Minas Gerais: Capitólio, MG-050, lado esquerdo da estrada, do lado direito vê-se o reservatório de Furnas, $21^{\circ} 04^{\prime} \mathrm{S}$, 46²6'W, 24.II.2000 (fl, fr), T.B. Cavalcanti et al. 2521 (holotypus: CEN; isotypi: $\mathrm{B}, \mathrm{BHCB}, \mathrm{MBM}, \mathrm{NY}, \mathrm{SPF}, \mathrm{W})$.

Subarbustos 0,40-1 m alt., com xilopódio, folhagem congesta, glauca a prateada; ramos ferrugíneos a avermelhados, pubescentes a curto-vilosos, indumento branco, fortemente quadrangulares e alados, ala 0,3-0,6 mm. Folhas 20-42 mm compr., 5-16 mm larg., suberetas, decussadas, acródromas basais, coriáceas, pecioladas, elípticas a estreitoelípticas, mais raramente oval-elípticas, ápice agudo, margem plana a raro subrevoluta, base aguda a raro obtusa, atenuada, lâminas macias ao tato, cobertas por indumento curto-viloso em ambas as faces, freqüentemente prateado a raro esverdeado-canescente, variando até indumento composto por tricomas diminutos e inconspícuos, neste caso sem o aspecto prateado; nervuras 3 de cada lado, partindo da base da nervura central, sulcadas na face abaxial; pecíolo 2,5-4 mm compr., largo. Sinflorescência congesta, frondosa a frondosobracteosa, do tipo diplobótrio a triplobótrio, florescência principal 20-30 cm compr., paracládios $15-25 \mathrm{~cm}$ compr., brácteas 15-25 mm compr., 5-10 mm larg., semelhantes às folhas vegetativas, de tamanho menor; hipopódio 1,5-2 mm compr., epipódio 1-1,5 mm compr.; profilos 10-11 mm compr., 3-3,5 mm larg., elípticos, ápice e base agudas, margem plana, ultrapassando as sépalas 1-2 mm; tubo floral 8-9 mm compr., prateado a esbranquiçado, curto viloso, ou coberto por indumento diminuto e inconspícuo, ocre-dourado na frutificação; sépalas 2,5-3,2 mm compr., triangulares, curtovilosas ou com indumento inconspícuo; segmentos do 

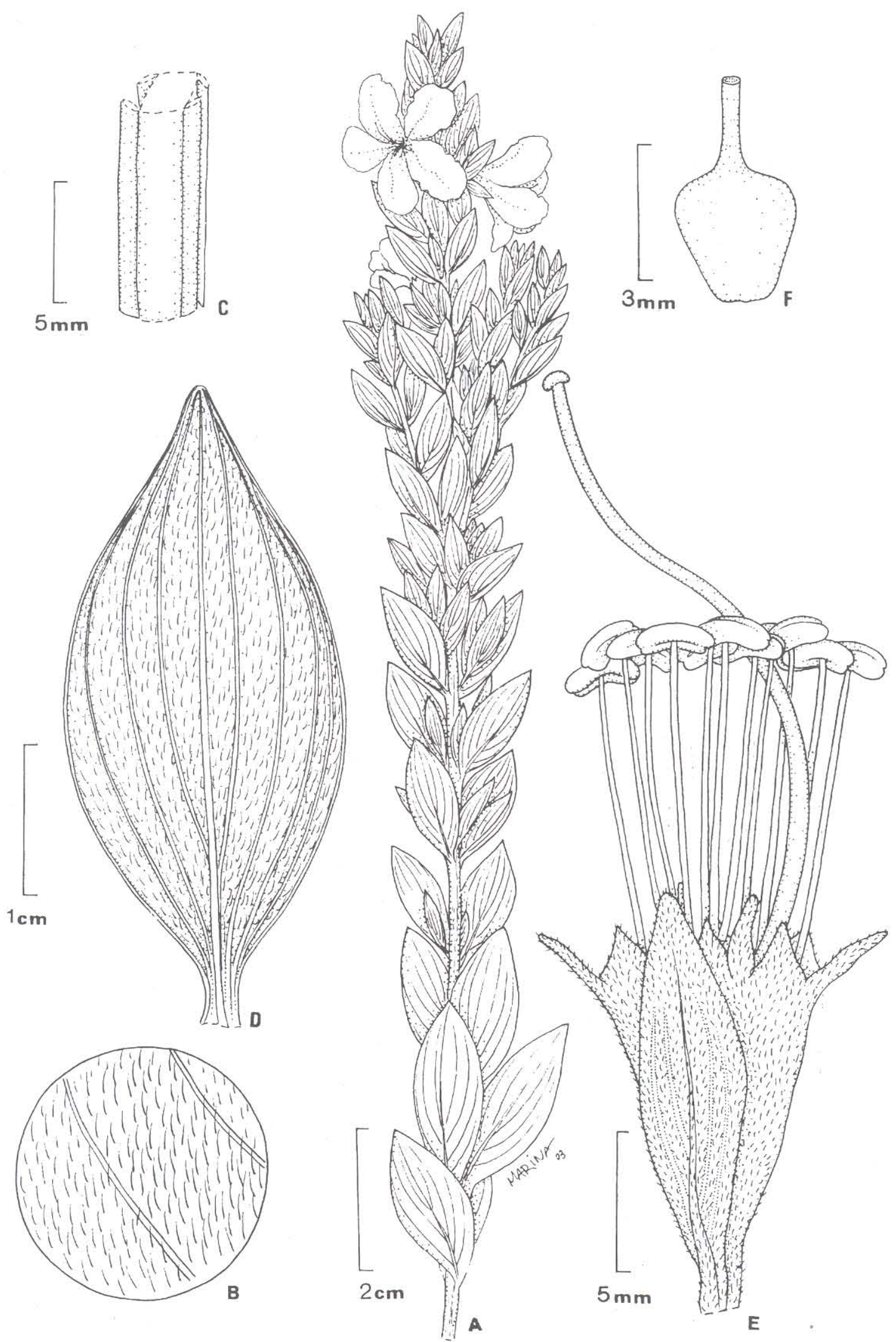

Fig. 4: Diplusodon glocimarii T. Cavalcanti. A. ramo ilustrando parte do hábito. B. detalhe do indumento da face abaxial da folha. C. seção transversal do ramo superior. D. folha, face abaxial. E. flor sem as pétalas. F. ovário. (A-F: Cavalcanti et al. 2521). 
epicálice 3-4,5 mm compr., com tricomas curtos e patentes ou diminutos e inconspícuos, lineares, achatados, patentes quando frescos, eretos quando secos; corola $2,5-3 \mathrm{~cm}$ diâm., lilás, pétalas 15-18 mm compr., 7-9 mm larg., elípticas a obovais; estames 12, porção livre dos filetes 12-14 mm compr., roxa, exsertos 5-6 mm; ovário 2-2,5 mm compr., 3-3,5 mm larg., glabro, obtrapezoidal,; estilete ca. $20 \mathrm{~mm}$ compr., vináceo, estigma verde, proeminentemente capitado, óvulos 33-38. Cápsula imatura oblonga a oboval; sementes ca. 26, 2,2-2,8 mm compr., 1,8-2,1 mm larg.

Paratypi: Brasil. Minas Gerais: Capitólio, estrada PassosPiumhi, a $45 \mathrm{~km}$ de Piumbi, arredores da represa de Furnas, $20^{\circ} 22^{\prime} 98^{\prime \prime S}, 46^{\circ} 11^{\prime 3} 3$ ”'W, 12.I.1994 (fl), V.C. Souza et al. 5049 (CEN, SPF); estrada vicinal da MG 050, à esquerda após o rio Grande, cerca de $1 \mathrm{~km}$ após a ponte, 2,4 km da MG-050,206' $\mathrm{S}$, 453' 'W, 24.II.2000 (fl, fr), T.B. Cavalcanti et al. 2513 (CEN, NY, RB). São Roque de Minas, Parque Nacional da Serra da Canastra, Cachoeira dos Rolinhos, 21.III.1996 (fl), J.N. Nakajima \& R. Romero 1664 (HUFU); 15.V.1999 (fl), M.A. Farinaccio et al. 320 (CEN, SPF).

A maioria dos indivíduos de Diplusodon glocimarii apresenta a coloração prateada em folhagem, devido ao denso indumento viloso. Outras populações cujos indivíduos tem folhas com indumento denso, apresentam coloração verdeacinzentada. Outras características diagnósticas da espécie são a presença de ramos fortemente quadrangulares, com ala conspicua e folhas estreito-elípticas a oval-elípticas, de nervação acródroma, formada por nervuras bem próximas umas às outras e eretas. $\mathrm{Na}$ flor pode-se ressaltar o longo tubo floral, com oito a nove milímetros de comprimento, acompanhado por longos profilos que ultrapassam o ápice das sépalas e 12 estames.

O epíteto especifico foi escolhido em referência a Glocimar Pereira da Silva (G. Pereira-Silva), geógrafo e conhecedor da flora brasileira, pela inestimável contribuição ao conhecimento das Lythraceae brasileiras através da incansável busca de espécimes e sementes desta família em suas expedições de coleta pelo Brasil.

5. Diplusodon petiolatus (Koehne) T.B. Cavalc., stat. nov. (Fig. 5)

Basionimo: Diplusodon lanceolatus Pohl var. alutaceus (Pohl) Koehne f. petiolatus Koehne, Fl. bras. 13 (2): 330, pr. 61, fig. 4b. 1877. Typus: Brasil. Goiás: 1841, G. Gardner 3724 [lectotypus: P; isolectotypi: G (2), K, OXF, NY (2), P (2), W (2); foto, CEN; aqui designado).

Subarbustos 0,60-1,6 $\mathrm{m}$ alt., com xilopódio; ramos laxamente dispostos, cilíndricos, cobertos por indumento denso, com tricomas espessos, curtos de diferentes tamanhos, desarranjados, formando às vezes tufos, internós $2-6 \mathrm{~cm}$ compr. Folhas 4,5-70 mm compr., 15-40 mm larg., suberetas, decussadas, eucamptódromas, cartáceas, levemente glaucas, pecioladas, elipticas a ovais, ápice agudo, atenuado, margem plana, base aguda a obtusa, lâminas pubescentes a hirtelas, nervuras 4-6 de cada lado ao longo da nervura central, nervuras terciárias muitas vezes evidentes; pecíolo 6-15 mm compr. Sinflorescência ampla e longa, começando quase desde a base da planta, bracteosa do tipo pleiobótrio, ramos delgados e delicados, com tricomas curtos de diferentes tamanhos, desenvolvimento de ramos acessórios de primeira e segunda ordem, curtos, florescência principal geralmente truncada., paracládios de $1^{\mathrm{a}}$ ordem $20-30 \mathrm{~cm}$ compr, paracládios de $2^{\mathrm{a}}$ ordem 10-15 cm compr., brácteas 20-30 mm compr., 7-10 mm larg., elípticas, com tricomas equinóides brancos, flores pecioladas, fortemente concentradas no ápice dos ramos, às vezes em tríades, às vezes formando glomérulos, hipopódio 1,5-2 (-3,5 no fruto), epipódio 1-1,5 (-2 no fruto); profilos 4-5 mm compr., 1-1,2 mm larg., estreito-oblongos, carenados, ultrapassando o tubo floral, margem plana, ápice agudo, tubo floral 4-5 mm compr., infundibuliforme, com constrição no ápice quando em fruto, canescente, tricomas muito curtos e densos, sépalas 1,5-2 mm compr., triangulares, papilas conspícuas, segmentos do epicálice 2,5-4 mm compr., mais longos que as sépalas ca. $1,5 \mathrm{~mm}$, cilíndricos e estreitos, eretos a suberetos, com tricomas equinóides brancos; corola ca. $2 \mathrm{~cm}$ diâm., rosachoque, pétalas 10-12 mm compr., 6-8 mm larg., elípticas, base aguda, ápice obtuso; estames 18 , tecas com tricomas, porção livre dos filetes 6-7 $\mathrm{mm}$ compr., pouco exsertos, anteras com tricomas, ovário 1,2-1,8 mm compr., 1,8-2 mm larg., obcônico, glabro, estilete 10-13 mm compr., óvulos 12. Cápsula oblonga; sementes $12,1,5-1,8 \mathrm{~mm}$ compr., 1-1,5 mm larg.

Material examinado: Brasil. Goiás: Arraias, estrada Arraias-Paranã, a $9 \mathrm{~km}$ da saída de Arraias, 12²5'93"S, 4659'78”'W, 5.IV.1997 (fl, fr), T.B. Cavalcanti et al. 2220 (CEN, KE-G); 12.II.1994 (fl), G. Hatschbach et al. 60423 (MBM, n.v., P); 15.II.1990 (fl), G. Hatschbach et al. 53996 (MBM, n.v., P). Campos Belos, $5 \mathrm{~km}$ após Campos Belos, 21.III. 1993 (fl, fr), T.B. Cavalcanti et al. 1254 (CEN, NY, SPF). Tocantins: Paranã, estrada Arraias-Paranã, a 53 km da saída de Arraias, 1243'87''S, 47²8'32"'W, 5.IV.1997 (fr), T.B. Cavalcanti et al. 2223 (CEN, KE-G, NY); idem, estrada Palmeirópolis-Alvorada de Goiás, a 25 km de Palmeirópolis, 1254'46"S, 48³3'42”'W, 6.IV.1997 (fr), T.B. Cavalcanti et al. 2230 (CEN); estrada São Salvador-Rosário, km 22, $12^{\circ} 51^{\prime} 50^{\prime \prime S}, 48^{\circ} 11^{\prime} 23^{\prime \prime} \mathrm{W}, 02$.VII.2002 (fl, fr), G. Pereira-Silva et al. 6492 (CEN).

Koehne (1877), baseando-se no material de Gardner 3724 , descreve Diplusodon lanceolatus var. alutaceus f. petiolatus, considerando o táxon como uma forma com folhas pecioladas, lâminas maiores e flores menores com número menor de estames. Essas características, somadas às outras observadas no material-tipo e em espécimes adicionais provenientes de coletas recentes, levam à conclusão de elevar o táxon proposto por Koehne (1877) à categoria de espécie. 


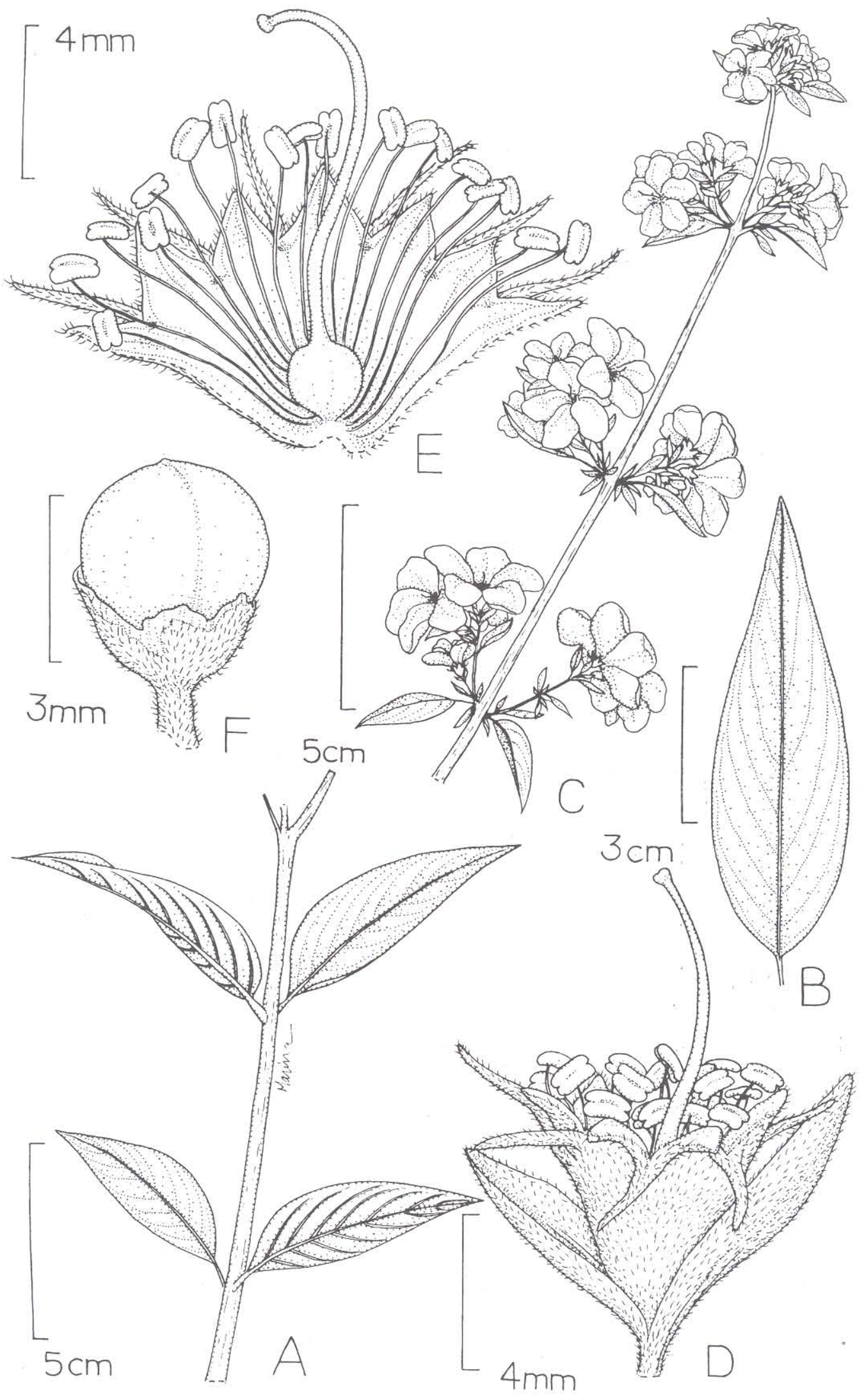

Fig. 5: Diplusodon petiolatus (Koehne) T. Cavalcanti. A. parte do ramo vegetativo. B. folha, face abaxial. C. parte da inflorescência. D. flor, sem as pétalas. E. flor em corte longitudinal. F. cápsula imatura. (A-E: Cavalcanti et al. 2220; F: Cavalcanti et al. 2223). 
Diplusodon petiolatus reúne uma série de características exclusivas, não encontradas em $D$. lanceolatus, podendo-se citar, na ordem de maior importância, a ampla e delicada inflorescência, com flores pequenas e delicadas, muito congestas, às vezes em tríades e formando glomérulos na porção apical dos ramos, segmentos do epicálice mais longos que as sépalas e com tricomas brancos e densos, 18 estames, anteras com tricomas nas tecas e folhas com longo pecíolo.

O material-tipo, Gardner 3724, possui diversas duplicatas depositadas em diferentes herbários da Europa. Não há conhecimento de que houve uma duplicata no herbário de Berlim, na qual Koehne poderia ter baseado as suas observações. Das três duplicatas depositadas no herbário do Museu de História Natural de Paris (Herbário P), uma delas contém uma etiqueta original, diferenciada pela cor azul, e com a identificação de Koehne como D. lanceolatus var. alutaceus f. petiolatus, indicando a página da "Flora Brasiliensis" onde consta o táxon. Este material foi o escolhido como lectótipo.

Diplusodon petiolatus ocorre em áreas de cerrado denso perturbado e campo sujo, em solo arenoso e latossolo vermelho, aos 400-442 m s.n.m. Flores foram registradas de janeiro a março e frutos em abril e maio.

6. Diplusodon punctatus Pohl var. dentatus T.B. Cavalc., var. nov. (Fig. 6)

A varietate typica tubo florali appendiculato, appendicibus usque ad $2.5 \mathrm{~mm}$ longis differt.

Typus: Brasil. Goiás: Cavalcante, balsa do Rio Tocantins (Serra Branca), para Serra Branca km 2, solo arenoso com afloramento de quartzo leitoso, $13^{\circ} 34^{\prime} 26^{\prime \prime} \mathrm{S}, 48^{\circ} 05^{\prime} 48^{\prime \prime} \mathrm{W}$, 23.V.2001 (fl), G. Pereira-Silva et al. 5084 (holotypus: CEN; isotypi: $\mathrm{K}, \mathrm{NY}, \mathrm{SPF}, \mathrm{W})$.

Subarbustos 1,0-1,7 m alt., com xilopódio; totalmente glabros quando adultos, ramos claros, amarelados, cilíndricos a achatados, internós $3-5,5 \mathrm{~cm}$ compr. Folhas 17-70 mm compr., 16-40 mm larg., decussadas, acródromas basais típicas, coriáceas, eretas, sésseis a subsésseis, glabras, levemente glaucas, ovais a oval-lanceoladas, com pontuações negras, ápice agudo a obtuso, margem plana, base obtusa, nervuras 2-3 de cada lado, partindo da base da nervura central; pecíolo ca. $1 \mathrm{~mm}$ compr. Sinflorescência bracteosa, laxa, delicada, do tipo pleiobótrio, florescência principal do tipo bótrio, 3-5 cm compr., paracládios 3-24 cm compr., brácteas 8-35 mm compr., 14-12 mm larg., ovallanceoladas a estreito-elípticas, margem plana, 1-2 nervura de cada lado; hipopódio 3-5,5 mm compr., epipódio ca. 0,5; profilos 5-7 mm compr., ca. $2 \mathrm{~mm}$ larg., oblongos, carenados na base, superando o ápice do tubo floral; tubo floral 4,5-5 mm compr., infundibuliforme, amarelo-esverdeado a paleáceo na frutificação, sépalas 1,5-2 mm compr., triangulares, às vezes curtamente ciliadas, segmentos do epicálice $3-4 \mathrm{~mm}$, patentes a pouco deflexos; corola ca. $2,5 \mathrm{~cm}$ diâm., rosa-choque, pétalas 9-10 mm compr., 4-6 mm larg., obovais, ápice obtuso; estames 12, porção livre dos filetes rósea a alva, 5,5-6,3 mm compr., exsertos; ovário ca. $2 \mathrm{~mm}$ compr., 1,5$2 \mathrm{~mm}$ larg., glabro, rômbico a arredondado, estilete 10 $12 \mathrm{~mm}$ compr., óvulos 16-18. Cápsula arredondada, sementes 13-16, 1,8-2 mm compr., 1,2-1,5 mm larg.

Paratypi: Brasil. Goiás: Cavalcante, estrada de terra que parte do "Porto Paulista" (balsa) no rio Tocantins para o Buracão, à ca. $4,9 \mathrm{~km}$ do rio, $13^{\circ} 28^{\prime} 06^{\prime}$ 'S, $48^{\circ} 07^{\prime} 08^{\prime \prime} \mathrm{W}$, 7.XI.2000 (fl, fr), B.M.T. Walter et al. 4549 (CEN); estrada Balsa "Porto Paulista" (rio Tocantins), à 1,8 km do rio, $13^{\circ} 29^{\prime} 13^{\prime \prime}$ 'S 4808'16"W, 7.XI.2000 (fl, fr), G. Pereira-Silva et al. 4365 (CEN); estrada Balsa "Porto Paulista" (rio Tocantins) para a Usina Hidrelétrica, ca. $32 \mathrm{~km}$ da balsa, $13^{\circ} 22^{\prime} 52^{\prime}$ 'S, 4800'00"W, 9.XI.2000 (fr), G. Pereira-Silva et al. 4402 (CEN, NY); estrada Minaçu-Cavalcante, passando pela Serra Branca (Coterra), à ca. $20 \mathrm{~km}$ do rio Tocantins, $13^{\circ} 40^{\prime} 17^{\prime \prime} \mathrm{S}, 47^{\circ} 54^{\prime} 41^{\prime \prime} \mathrm{W}, 10 . \mathrm{XI} .2000$ (fr), G. Pereira-Silva et al. 4417 (CEN, NY); vila Veneno-estrada São Felix, km 4, 1333'55'S, 4804'34'W, 27.VI.2001 (fl, fr), G. Pereira-Silva \& Carvalho-Silva 5208 (CEN). Minaçu, margem da estrada Minaçu-Serra da Mesa, a 7 $\mathrm{km}$ do canteiro de obras da AHE Serra da Mesa, antigo viveiro, 13³4'S, 48¹0'W, 11.X.1991 (fr), T.B. Cavalcanti et al. 1014 (CEN-2); depois de Buriti, $18 \mathrm{~km}$, estrada

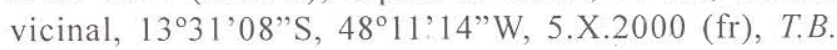
Cavalcanti et al. 2662 (CEN). Tocantins: Palmeirópolis, estrada Palmeirópolis-Alvorada do Tocantins, a $35 \mathrm{~km}$ de Palmeirópolis, 1257'75S, 4834'41'”, 6.IV.1997 (fl), T.B. Cavalcanti et al. 2227 (CEN). Paranã, estrada Palmeirópolis-Alvorada de Goiás, a $25 \mathrm{~km}$ de Palmeirópolis, 1254'46"S, 48³3'42"W, 6.IV.1997 (fl), T.B. Cavalcanti et al. 2229 (CEN, NY).

Diplusodon punctatus var. punctatus é excepcional no gênero pela ausência total de epicálice. Em uma mesma região ocorrem populações vegetativamente semelhantes, com flores de mesma forma e número de estames. Entretanto, algumas populações apresentam flores com um epicálice bem definido, com seis apêndices evidentes e patentes. Optou-se por considerar para essas populações, a categoria de variedade, especialmente por ocuparem a mesma região de distribuição da variedade típica e não ocorrer barreiras geográficas entre as mesmas.

Diplusodon punctatus Pohl var. dentatus ocorre em áreas de campos cerrados e campos sujos e foi coletada com flores de abril a junho e com frutos em de outubro a junho. 


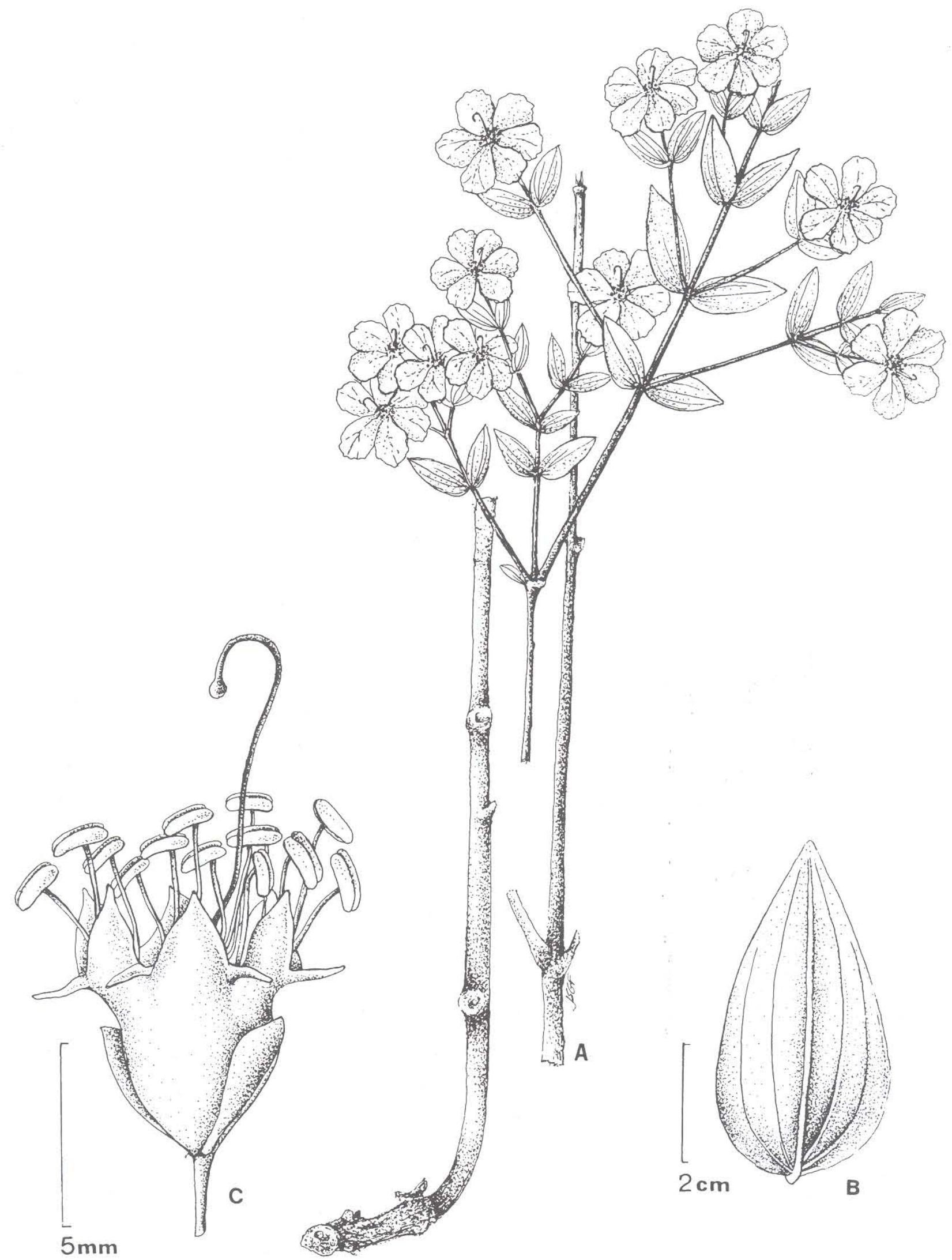

Fig. 6: Diplusodon punctatus Pohl var. dentatus T. Cavalcanti. A. parte do ramo hábito. B. folha, face abaxial. C. flor, sem as pétalas. (A-C: Pereira-Silva et al. 5084). 


\section{Agradecimentos}

A autora agradece à Embrapa Recursos Genéticos e Biotecnologia pela infra-estrutura para as expedições de coleta e ao CNPq pelo apoio a esta pesquisa. Agradece também à Micheline Carvalho Silva pelo constante apoio e auxílio na logística dos estudos de revisão do gênero Diplusodon, à Marina de Souza Gomes, Emiko Naruto e Jeanitto Sebastião Gentilini pelas ilustrações deste trabalho, e ao Tarciso Filgueiras pela elaboração das diagnoses em latim.

\section{Referências}

CAVAlCanti, T.B. 1987. Lythraceae. Bol. Bot. Univ. S. Paulo 9: 66-67.

CAVAlCANTI, T.B. 1990. Flora da Serra do Cipó, Minas Gerais. Lythraceae. Bol. Bot. Univ. São Paulo 12: 67-93.
CAVALCANTI, T.B. 1991. New species of Cuphea (Lythraceae) from Brazil. Kew Bulletin 46(2): 253-268.

CAVAlCANTI, T.B. 1995. Revisão de Diplusodon Pohl (Lythraceae). Tese de Doutorado, Universidade de São Paulo. São Paulo.

CAVALCANTI, T.B. 1998. New species of Diplusodon (Lythraceae) from Brazil. Novon 8(4): 337-351.

CAVALCANTI, T.B. \& GRAHAM, S.A. 1996. Diplusodon bolivianus sp. nov. (Lythraceae), the first report of the genus for Bolivia. Novon 6(3): 253-255.

CAVALCANTI, T.B., GRAHAM, S.A. \& CARVALHO-SILVA, M. 2001. Lythraceae. In J.A. Rizzo (ed.) Flora dos estados de Goiás e Tocantins, Coleção Rizzo. Universidade Federal de Goiás, Goiânia, vol. 28 , p. 1-150.

GRAHAM, S.A. \& CAVALCANTI, T.B. 2001. New chromosome counts in the Lythraceae and a review of chromosome numbers in the family. Syst. Bot. 26(3): 445-458.

KOEHNE, E. 1903. Lythraceae. In G.H.A. Engler (ed.) Das Pflanzenreich. Wilhelm Engelmann. Leipzig, IV. 216, p. 1-326.

LOURTEIG, A. 1989. Lythraceae Austroamericanae. Addenda et corrigenda III. Bradea 5 (19): 205-241. 